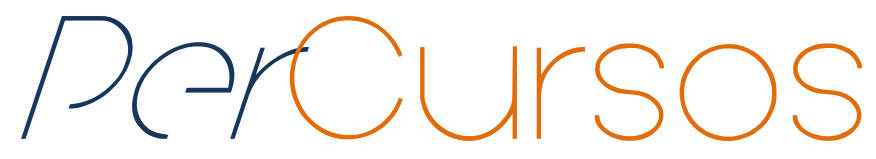

\title{
Estado, exílio e educação: diálogos contemporâneos a partir da sociedade brasileira
}

\section{Resumo}

O trabalho objetiva pensar as possíveis relações entre Estado, Exílio e Educação, ao estabelecer diálogos contemporâneos a partir da sociedade brasileira. Sua caracterização alinhava o golpe de 1964, a ditadura instaurada e o exílio brasileiro até 1980, orientando-se a partir dos percursos de Elza Freire entrelaçados ao de Paulo Freire, seu esposo. Justifica-se tanto pelo caráter histórico ao discutir fatos passados, quanto pela ponte que estabelece com o presente/futuro na construção de sociedades mais igualitárias e menos autoritárias. Os cenários compõem-se entre o nacional e o internacional, onde foram inseridos brasileiros como parte do processo que acometeu homens e mulheres exilados, sempre vinculados às questões do seu país de origem. O foco é o exílio - enquanto ato imposto pelo Estado, como experiência social, coletiva e ao mesmo tempo individual e, sua relação com a dimensão político-pedagógica. O teórico-metodológico se fundamenta na abordagem qualitativa com mapeamento bibliográfico, fontes documentais e não documentais. Assim, descrever percursos, reunir memórias, investigar processos, são formas de impedir a repetição de governos ditatoriais, de recusar situações sociais de controle, opressão, exclusão e, violação de direitos; é fortalecer a educação e a sociedade civil e os princípios de liberdade e vida.

Palavras-chave: Educação e Estado; Freire, Paulo; 1921-1997 - Exílio; Freire, Elza; Exílio.

\author{
Nima Imaculada Spigolon \\ Doutora em Ciências Sociais \\ pela Universidade Estadual de \\ Campinas - UNICAMP. Professora \\ da Universidade Estadual de \\ Campinas - UNICAMP. \\ Brasil \\ nima@unicamp.br
}

\section{Para citar este artigo: \\ SPIGOLON, Nima Imaculada. Estado, exílio e educação: diálogos contemporâneos a partir da sociedade brasileira. Revista PerCursos, Florianópolis, v. 17, n.35, p. 175 - 200, set./dez. 2016.}

\section{DOI: $10.5965 / 1984724617352016175$}

http://dx.doi.org/10.5965/1984724617352016175 


\title{
State, exile and education: contemporary dialogues from the brazilian society
}

\begin{abstract}
The job objective thinking the possible relations between State, Exile and education, to establish contemporary dialogues from the Brazilian society. His characterization was already in the 1964 coup established dictatorship and exile until 1980, Brazilian from the paths of Elza Freire entwined to Paulo Freire's your spouse. Is justified by both the historic character to discuss facts, and the bridge with the present/future in building more egalitarian and less authoritarian societies. The scenarios consist between the national and the international, where Brazilians were inserted as part of the process that involved men and women exiled, always linked to the questions of their country of origin. The focus is to discuss the exile-while tax act by the State, as social experience, collective and individual and at the same time, his relationship with the political-pedagogical dimension. The theoreticalmethodology is based on a qualitative approach, taking as departure bibliographic mapping, documentary and non-documentary sources. So, describe courses, retrieve memories, investigating processes, is a way to prevent the repetition of dictatorial governments, is refuse social situations of control, oppression, exclusion and violation of rights, is to strengthen education and civil society and the principles of freedom and life.
\end{abstract}

Keywords: Education and State; Freire, Paulo; 1921-1997 - Exile; Freire, Elza; Exile. 


\section{Introdução}

Sem condições de aprofundar, é importante analisar que aconteceu no Brasil o golpe de 1964 e foi instaurada a ditadura como parte do processo histórico das transformações econômicas, políticas e sociais em curso na sociedade brasileira. Os acontecimentos advindos desse processo marcaram as memórias, a história do país e a vida dos indivíduos; dentre eles, o exílio, que engloba uma multiplicidade de condições sociais coadunadas às situações particulares dos indivíduos.

É um tempo que permanece vivo e que na contemporaneidade se faz presente na pauta dos diálogos urgentes em interface com o Estado e a Educação. Elias (1998) sustenta que o tempo não existe em si mesmo, sendo antes um símbolo social, resultado de longo processo de aprendizagem. Processo que, passados 50 anos, no Brasil, nada há, pois a celebrar. Ao contrário, devemos aprender sempre e relembrar: Ditadura, nunca mais!

No compasso desse processo e experiências ${ }^{1}$, o tempo e a história interagem memória e passado/presente/futuro, dão movimento à propagação de visões de mundo construídas no cotidiano de práticas sociais repletas de utopias, registra "o que nos passa, o que nos acontece, o que nos toca" (LARROSA, 2002, p. 20).

Exílio, Educação e a utopia ${ }^{2}$ que ainda sangram sob os golpes de Estado e das lutas cotidianas, pulsam na sociedade brasileira em diversos tempos, espaços, lugares de uma realidade.

É uma relação dialética, "a utopia concreta fundamenta-se no movimento de uma realidade cujas possibilidades ela descobre. Dialeticamente, o possível é uma categoria da realidade" (LEFEBVRE, 2008, p. 15). Portanto, é essa dialética que direciona para as

\footnotetext{
${ }^{1}$ O sentido empregado é o adotado por Larrosa, pois, como ele, propomos "pensar a Educação a partir do par experiência/sentido [...] é em primeiro lugar um encontro ou uma relação com algo que se experimenta, que se prova [...] tem sempre uma dimensão de incerteza" (LARROSA, 2002, p. 20-28).

${ }^{2}$ O conceito que adotamos se ancora em Vázquez (2001); Lefebvre (2008); Pepetela (1997); Galeano (2007) e Freire (2000). Como os autores aqui, o sentido empreendido é que a realidade também é a utopia, já que é a partir do que se vive no real que se projetam as ideais, os sonhos, as esperanças de um futuro melhor e é feita a partir dos movimentos de transformação dessa realidade.
} 
possibilidades de mudanças, "não existe [...] uma muralha que separe a realidade e a utopia; uma conduz à outra" (VÁSQUEZ, 2001, p. 320).

Uma imagem representativa para se pensar no futuro e nas utopias é a do horizonte. O horizonte é revelador, pois, historicamente, o futuro vai sendo transformado em presente. O horizonte é infinito, é fronteira entre presente e futuro.

Janela sobre a utopia [...] Ela está no horizonte - diz Fernando Birri. Me aproximo dois passos, ela se afasta dois passos. Caminho dez passos e o horizonte corre dez passos. Por mais que eu caminho, jamais a alcançarei. Para que serve a utopia? Serve para isso: para caminhar. (GALEANO, 2007, p. 310)

A possibilidade de pensar para além dessa fronteira é um dos elementos centrais da emancipação humana, pois apesar dos condicionamentos sociais e culturais das sociedades divididas em classes, há um espaço de reflexão e ação autônoma que permite a construção de uma consciência acerca da dominação vigente com potencial de superála.

De tal maneira que o artigo se insere nessa utopia, reflete sobre as relações implicadas entre Estado, Exílio e Educação e problematiza a sociedade brasileira na contemporaneidade ao estabelecer conexões de sentido a partir dos percursos de exílio e das experiências vividas por Elza Freire ${ }^{3}$ e sua família.

Para tanto, provoca deslocamentos, aproximações e distanciamentos ao lançar mão de resultados de pesquisa ${ }^{4}$ caracterizados a partir da descrição, análise e interpretação dos percursos de Elza Freire e sua família, sempre vinculados ao trabalho

3 Elza Maia Costa Oliveira nasceu em 1916, no Recife. Concluiu o magistério em 1935. Concursada, atuou como professora e diretora. Ao mesmo tempo, trabalhou no MEB, no MCP e nos Círculos de Cultura, até 1964 - quando estava em Brasília para o PNA e veio o golpe, tornando a família exilada. O retorno ao Brasil se dá em 1979, e em definitivo em 1980, sendo que em 1986 ela falece. Após o casamento com Paulo Réglus Neves Freire, passa a assinar Elza Maia Costa Freire. O casal passa a ser conhecido nacional e internacionalmente como: Elza Freire e Paulo Freire (SPIGOLON, 2009; 2014).

4 Esta pesquisa, em nível de Doutorado (2010 a 2014), contou com bolsa DS/CAPES e a realização de campo empírico no período contou em diversos momentos com financiamento, por exemplo: Fundo de Apoio ao Ensino, à Pesquisa e Extensão (FAEPEX), da UNICAMP; Programa de Bolsas de Mobilidade Internacional Pós-Graduação 2013 Santander Universidades; Programa de Centros Associados de Pós-Graduação (CAPG/BA). 
no campo da Educação de modo geral e, da Educação de Adultos, de modo particular, apresentados aqui no recorte temporal que compreende o golpe de 1964, a ditadura e exílio brasileiro entre 1964/1980.

No seu decorrer, há vestígios tanto do caráter memorialístico, ao discutir fatos passados, quanto da ponte que estabelece com a utopia do presente/futuro, ambos em oposição às ditaduras no Brasil, na América Latina e no mundo. Contra esse estado de coisas temos que insurgir, reafirmando uma educação libertadora e de corte universalista que vise à construção de sociedades mais justas, dignas, humanas e amorosas.

Os cenários rompem as fronteiras do nacional e do internacional, nos quais foram inseridos brasileiros como parte de um processo que acometeu homens e mulheres exilados, e também crianças e famílias. Processo que estimula a reflexão sobre a sociedade brasileira, o Estado, a Educação e a viabilidade em discutir itinerários de coletivos acometidos pelas ditaduras de Estado que cercearam direitos humanos, políticos e civis, que capturando a construção da democracia produziram violência, perseguição e exílios.

São cenários nos quais as experiências de Elza Freire, se entrelaçam a de tantos outros partícipes desse processo, alguns conhecidos, muitos desconhecidos. Ou seja, o foco é o exílio - enquanto ato imposto pelo Estado, como experiência social, coletiva e ao mesmo tempo individual e sua relação com a dimensão político-pedagógica. O exílio pode ser compreendido como mecanismo de perseguição, eliminação e afastamento de grupos questionadores e/ou opositores da ordem estabelecida a partir do golpe de 1964 e expulsos pela ditadura.

O protagonismo em Elza Freire compõe um trabalho quase que arqueológico para reunir memórias de brasileiro(a)s que viveram o exílio e sofreram, entre outras violências, a exclusão de participação na vida pública, política e intelectual do país; que tiveram experiências marcadas pelas circunstâncias governamentais da época e, agora são material empírico para fundamentar e inspirar reflexões críticas, que de forma concomitante influenciam e assumem caráter propositivo para formulação e execução de políticas públicas. 
O exílio foi consequência do aparato violento utilizado pelos militares para manterem-se no poder por mais de duas décadas (1964/1985), e atingiu direta ou indiretamente homens e mulheres, crianças e famílias que saíram do país, independente do seu grau de envolvimento com os acontecimentos, tornando-os alvo da repressão.

Alinhamo-nos à ideia de Yankelevich (2002; 2004; 2007) cuja perspectiva é de que o exílio, embora seja um ato de violação dos direitos humanos e terrorismo de Estado como mecanismo de exclusão política, desenvolve um papel fundamental nas configurações das relações nacionais, latino-americanas e mundiais. A experiência de ser exilado, para o indivíduo e o grupo submetido a ele, representa fundamentalmente

[...] comporto dolor y sufrimento - desarraigo, perdida de identidad, la interrupción violenta de todas las actividades de la vida cotidiana [...] uma violación de los Derechos Humanos; por último, los exilados realizaron uma labor política de denuncia internacional del terrorismo de Estado $^{5}$. (YANKELEVICH; JENSEN, 2007, p. 11)

O exílio marca a história da humanidade. Rollemberg (1999), Costa [et. al. 1980], Rabêlo (2001) sugerem que cada exílio é definido por conjuntura específica e problemas próprios à época e ao lugar. Entretanto, há elementos comuns que são percebidos nos exílios de diversos povos, em diferentes culturas e momentos. Não há um exílio, mas muitos exílios.

Sobre a força das experiências e recordações de situações adversas e diversas vividas pelos exilados, Said (2003) escreve que

O exílio nos compele estranhamente a pensar sobre ele, mas é terrível. Ele é uma fratura incurável entre um ser humano e um lugar natal, entre o eu e seu verdadeiro lar: sua tristeza essencial jamais pode ser superada. E embora seja verdade que a literatura e a história contêm episódios heróicos, românticos, gloriosos e até triunfais da vida de um exilado, eles não são mais do que esforços para superar a dor mutiladora da separação. As realizações do exílio são permanentemente minadas pela perda de algo deixado para trás para sempre. (SAID, 2003, p. 46)

\footnotetext{
${ }^{5}$ Textos em espanhol e/ou outros idiomas, optamos por mantê-los na forma original.
} 
Então, o fazer científico, as reflexões críticas e dimensões mais sensíveis, expressam o desejo de que a face do(a) exilado(a), aqui representado por Elza Freire, Paulo Freire e sua família esteja em cada parágrafo do texto e, ao fim, se possa ter uma percepção do exílio e dos significados atribuídos a essa experiência, em relação com o Estado e a Educação. Said, acima, ao declarar que "o exílio nos compele estranhamente a pensar sobre ele", ratifica o convite de agora "pensar sobre ele", o exílio e, também sobre ela, Elza Freire e, os dois juntos para pensarmos o Brasil e a sociedade brasileira.

É, pois, também na dimensão dessas indagações que se inscreve o presente trabalho.

\section{Golpes: civil-militar, de 1930 e 1964, na educação}

Há razões para discutir antecedentes aos golpes ${ }^{6}$, porém o período de transição que vai de1930 a 1964 é significativo em relação a outros ao subsidiar o entendimento da formação do Estado brasileiro. O que interessa é descobrir no processo histórico, o papel e função das forças sociais que atuaram nesses cenários e de que formas concretas elas atuaram no confronto com as demais e, que foram se imbricando ao processo do exílio.

Segundo Weffort (1978), o Estado que surge da Revolução de 30, é um "Estado de compromisso"; nele se encontram presentes tanto as velhas oligarquias agrárias como as forças sociais urbanas em ascensão. Em termos mais amplos, os anos de 1937 a 1945, trazem o Estado Novo e o sistema centralizador implementado por Getúlio Vargas, quando as preocupações presentes entre os intelectuais era definir o Estado moderno e interpretar as relações entre a vida econômica e a estrutura política, apontando indícios do povo brasileiro que desejavam "formar".

\footnotetext{
${ }^{6}$ A análise de Dreifuss sintetiza os principais argumentos da interpretação "marxista" do golpe e considerou que a conquista do Estado pelo bloco de poder ligado a este não constituiu "um mero reflexo da supremacia econômica", mas "um resultado de uma luta política empreendida pela vanguarda destes novos interesses" (DREIFUSS, 2008, p. 482). Assim, o golpe de 1964, pode ser tido como golpe civil-militar, em decorrência da atuação de relevantes setores da sociedade civil e militar, organizados em forma de blocos de poder, como: o bloco econômico multinacional e associado, autoridades eclesiásticas, intelectuais e políticos de orientação liberal-conservadora, meios de comunicação e mídia, demonstrando que era necessário "conquistar o Estado" e, para isto, esse novo bloco de poder partiu para a conspiração.
} 
A partir do final do Estado Novo, em 1945, até o regime militar iniciado em 1964, de acordo com Vita (2001), foi possível às classes populares urbanas participarem da vida política e do Estado; porém subordinadas a líderes e partidos políticos ligados às classes dominantes da sociedade, caracterizando o populismo.

O nacionalismo constituiu-se fortemente na década de 1950 e início de 1960, período em que, de acordo com Weffort (1978), a ideologia nasce dentro do Estado ou em associação com ele, embora pretendendo traduzir os interesses gerais de todo povo.

Sendo assim, estas décadas "engendram um conflito irremediável" que se traduziu nas contradições criadas pela polarização de forças oriundas da tomada de consciência do processo nacional-desenvolvimentista, fundamentado nas especificidades do país contrárias à internacionalização da economia, e do projeto modernizador que colocou em marcha o modelo financiado pelo capital estrangeiro que cobrava o alinhamento do Brasil ao imperialismo norte-americano, contrário à autonomia do país (MAZZA, 2003).

No Brasil, o importante a destacar nessa fase é a ação e mobilização políticoideológica no cenário educacional e cultural, que refletia uma crítica sócio-histórica. Nos últimos anos da década de 1950 e princípio da de 1960, enfatiza Dreifuss (2008) que estudantes, intelectuais, políticos e militantes de partidos, clérigos e militares desenvolveram um movimento, num racional e planejado esforço de conscientização das massas que visava a despertar em seu meio um senso de consciência de seu verdadeiro e potencial valor a fim de prepará-las como participantes e beneficiárias da mudança social.

Em face disso, com traços muito gerais, entre o auge do populismo, a crise de hegemonia política e a aceleração do desenvolvimento econômico, se identificam no bojo desses acontecimentos as repercussões dos movimentos mais expressivos e significativos de Educação, Educação Popular e Cultura Popular do Brasil?.

\footnotetext{
7 Autores pormenorizam a temática: Freire (1967); Fávero (1983); Beisiegel (1974; 1982).
} 
Cabe registrar o envolvimento e o desempenho de Paulo Freire e sua equipe, que contava com a participação e influência decisiva de Elza Freire ${ }^{8}$, desde as primeiras experiências com o Sistema Paulo Freire de Alfabetização e Conscientização (1960, Recife) até o Plano Nacional de Alfabetização - PNA (1962/1964, Brasília), tanto pelo importante papel que desempenharam nos confrontos desse período, quanto pela necessidade de sua inserção nesses cenários. Certamente, dois fatores coadunam com a conjuntura do início dos anos 60 e com o impulso dado ao Sistema Paulo Freire; o primeiro se deve aos dados de que mais de 50\% da população maior de 14 anos não era alfabetizada, ocasionando certa consciência sobre a gravidade social do problema do analfabetismo no Brasil"; o segundo, ao "impulso ideológico" de toda uma geração que se lançou no plano sociocultural através de ações educativas com forte conteúdo políticoideológico.

É o Brasil da década de 1960 que ainda tende a ignorar as responsabilidades que Ihe cabem, em virtude da situação educacional da sociedade brasileira, e que necessita ter à frente das discussões os problemas educacionais que se impõem, pois

[...] Em um país no qual a parte analfabeta da população abrange nada menos que $50 \%$ do total e em que a educação escolarizada ainda representa um privilégio, é imperioso fazer-se indagações suscetíveis de esclarecer como e por que necessidades educacionais básicas deixam de ser atendidas ou são enfrentadas de modo deficiente[...] (FERNANDES 1960)

Cenários da época e o espírito de um tempo se deixam marcar pelo desafio de um novo projeto histórico para o Brasil, que supunha uma nova visão de mundo e a descoberta de outra dimensão da consciência. Era necessário acertar os ponteiros políticos e sociais com o avanço das conquistas econômicas. Fazer tornar-se um lugar comum e de prioridade a convicção de que o desenvolvimento econômico, político e social do Brasil depende, diretamente, de planos e ações de re-construção educacional.

8 Remissão à SPIGOLON, 2009; 2014.

9 Em particular a ineficácia das Campanhas que se restringiam à mera alfabetização, as críticas apontavam a necessidade de encontrar novas diretrizes para a educação de adultos, de modo a torná-la funcional à sociedade brasileira em transformação. Consultar IBGE e Paiva (1973, p. 207). 
Consideramos que o recuo temporal favorece a rememoração dos episódios que antecederam ao golpe civil militar em 1964, bem como o próprio. E, através dele, refletir sobre os processos tortuosos da Democracia, da Educação e da Sociedade Brasileira. Destacamos que os caminhos para o recuo incluem o nordeste e, em especial Recife, o que representou uma ocasião propícia para aproximações e apropriações possíveis em torno dos percursos de Elza Freire, pois, de um lado trata de um momento particular da história de nosso país, um tempo de repressão em que homens e mulheres idealistas, partidários da democracia e da liberdade sofreram autoritarismos de variados quilates, foram obrigados a habitar celas de inquérito e prisões; e de outro: Elza Freire faz conhecer não apenas os seus percursos e o de sua família, mas igualmente o de muitos outros brasileiros, militantes, homens e mulheres feitos prisioneiros de cárcere aberto a partir dos cenários construídos e das configurações discutidas.

Era o intolerável, pode o ser ainda... O diálogo por vezes era e é a violência ${ }^{10}$.

A digressão às décadas anteriores e acontecimentos selecionados justifica-se para proporcionar amplo panorama da Sociedade Brasileira no pré-64. A conjuntura econômica, a luta pelas reformas sociais nas dimensões políticas e ideológicas, os movimentos populares e culturais, o papel dos militares e o fracasso das esquerdas, inclusive o pensamento da esquerda brasileira na Educação, a participação norteamericana e o alinhamento ao capital estrangeiro, os conflitos entre os blocos de poder engendrados pela força das concepções golpistas presentes na sociedade brasileira são alguns dos aspectos analisados.

Controvérsias, documentadas ou não, para que se mitigue, se esqueça, insuflando as gerações a serem indiferentes, até mesmo da composição civil e militar desse bloco histórico e da crueldade dos setores sociais que passam a exercer forte poder no país a partir de 1964. Não é simplesmente, volver ao passado e atinar para as discussões dos conflitos acirrados que se expressaram antecedendo aos golpes, sobretudo, ao de 1964 . Pensamos que o fato é ainda identificar, sentir, conviver com a presença continuada de

\footnotetext{
${ }^{10}$ Sugiro remissão às autoras, como por exemplo: Valle (2008) e Rezende (2001).
} 
uma ruptura irreversível de uma época, cujo espírito de um tempo ainda paira sob a sociedade brasileira.

A marcação do período e a construção dos cenários objetivam entender melhor os conflitos acirrados que rentes ao golpe civil-militar de 1964 trazem o despontamento dos Estados Unidos como grande potência mundial após a Segunda Grande Guerra e a adequação nacional à internacionalização capitalista, sendo perceptível a ofensiva do governo e das forças populares ${ }^{11}$. Existiram também vários projetos em processo da LDB (1961) e a proposta político-pedagógica voltada para a cidadania popular, sendo enfatizada a democratização da educação e da cultura popular.

Ao considerar tais questões, são nítidos os conflitos advindos do período, que tiveram início no pretérito, antes de 1964, demonstrando uma temporalidade que resiste até o presente. Os conflitos, de fato, eram mais profundos, seus cenários apresentavam essas materialidades históricas, ainda remanescentes. Segundo Sanfelice eclodiram

[...] rupturas que se fariam com o movimento civil-militar de 1964, atingindo globalmente a sociedade, já se delineavam ao longo dos anos de 1950. Estes anos tinham, então, contraditoriamente, a presença ainda do passado pré-1930, a sua temporalidade própria e o futuro, o pós-64 em construção. (SANFELICE, 2007, p. 545)

Florestan Fernandes (1975) tem o intento de dar uma resposta à situação política por que passava o país em meados da década de 1960, por meio da análise detalhada do processo que culminou com o golpe militar de 64. Para ele, o pressuposto inicial da análise é tratar o golpe não de maneira isolada e, sim entender o processo histórico das transformações econômicas, políticas e sociais que ocorreram na sociedade brasileira.

Assim, coadunada com essa perspectiva, acontece a elaboração das cenas, cuja intenção é identificar processos e compreender como essas características foram se conjugando até formar o cenário, privado e público que resultou, dentre outros fatos, na extinção deles e na criação de outros mediante o golpe de 31 de março de 1964, que vinha

\footnotetext{
${ }^{11}$ Autores que contribuem para uma elucidação histórica e análises mais críticas e abrangentes dessas questões: Dreifuss (2008); Gorender (1987); Rabêlo (2001); Starling (1986); Toledo (1982) e Santos (1962).
} 
sendo construído há tempos e, fez de forma figurada a noite da ditadura cair sobre o Brasil e amanhecer como exílio.

Entendemos que acabamos de evocar, como a brasa dormida de um acontecimento histórico que remete desde a luta social, coletiva e libertária, aos subterrâneos do poder e da opressão que me despertam uma questão crucial: quando será o outro golpe militar a recair sobre o Brasil como ação do Estado, da sua própria dinâmica de funcionamento e vasto apoio de determinados setores sociais, encobrindo utopias, provocando exílios? Ao mesmo tempo, problematizamos qual o papel da Educação para a construção de sociedades, de modo geral e, de modo particular, de sociedades mais justas, igualitárias e menos autoritárias?

Tais fatos reforçam-nos a apontar que foram também "golpes na Educação"12. Desde o princípio do texto, mas pensando no seu desenvolvimento, levamos em consideração fatos que pudessem apontar a Educação laica, pública, gratuita, de qualidade e socialmente referenciada, para todos e todas, em todos os níveis e modalidades como parte do projeto republicano e, nesse sentido, relacioná-la com o Estado, a Política e a Sociedade em diálogos permanentes ante à contemporaneidade.

Embora reconheçamos que o referido projeto apresenta diferentes matizes de classes, temporalidades e prioridades distintas de acordo com os interesses dos grupos e bloco de poder envolvidos na luta pela ocupação do Estado, é na busca de estabelecer uma aproximação entre a utopia política de um país democrático e socialmente justo, que encontramos a razão de lutar por uma Educação laica, gratuita, de qualidade e para todos, que se constitui processo para o país e revolução para sua população; por isso, problematizar a discussão dessa temática, construir cenários, inserir percursos, mantém vivo o espírito desta luta, pois que "nas sociedades em desenvolvimento, os "problemas sociais" não raro constituem, ao mesmo tempo, reflexos do desenvolvimento e pontos de estrangulamento deste processo como é, por exemplo, o caso dos problemas de Educação no Brasil atual" (NOGUEIRA, 1958, p. 26).

\footnotetext{
${ }^{12}$ Destacamos, principalmente, as discussões de Cunha \& Goés (1985).
} 
É essa a relação, Estado, Sociedade e Educação que defendemos e provocamos a pensar, do movimento sempre sob a chave do conflito e nunca da unanimidade, pois foi e é isso que ainda vivemos: o processo de redemocratização do Brasil, cujo início nos remete à Proclamação da República e à Revolução de 1930, foi revivido em 1945, vivenciou a ditadura de 1964, sobreviveu ao exílio e presenciou o início da abertura política em 1980, e vive até hoje, eis parte do argumento.

\section{Caminhos e campos teórico-metodológicos}

O teórico-metodológico se encontra em permanente construção. A partida é o mapeamento bibliográfico. Iconografias, fontes primárias, documentais e não documentais, estruturam-se numa lógica indutiva e compõem, juntas, intertextualidades. Os aportes da abordagem qualitativa fundamentam esse caminho.

Identificamos na diversidade das fontes um instrumento que se sobressai para descrever o quadro político-pedagógico, sócio-histórico, econômico e cultural, entendido como manifestações de uma época sob o espírito de um tempo. Por exemplo, ao considerar vertentes artísticas e literárias, com matizes conscientizadoras, voltadas para a problemática da sociedade, trazemos para o texto e atribuímos a elas, resultados do caminho percorrido pelas pesquisadoras na tentativa de realizar uma composição mais variada e sensível que, ao tratar dessas questões, mantenha critérios e rigores científicos.

Brühl sustenta que a decisão sobre utilização e composição de métodos não deve ocorrer independentemente ou à margem do conteúdo e dos problemas a serem pesquisados. Para o autor, os “métodos são ‘humanização da ciência”. Seu posicionamento faz entender que o movimento da dialética no processo de pesquisa como em qualquer processo social é básico para "a conceituação do processo de pesquisa, a metodologia" ( Brühl, [19--], p. 06).

Quando se define isso em nível de reflexão teórico-metodológica, estabelecemos relação com tal procedimento, que capta e permite a interação com/entre o sujeito da pesquisa, o qual se afigura como na medida em que o percurso de Elza Freire regula e configura as temporalidades da pesquisa. Então, sobre o "método correto" Brühl aponta 
como limites: o tempo e o espaço da realidade, concluindo que "os métodos são, portanto, "corretos" na medida em que eles sejam aplicáveis dentro dos limites que o tempo e o espaço Ihes impõem" (S/d; S/Ed., p. 03). Acreditamos que sejam eles os contornos da pesquisa, cujo ponto de partida e retorno é o Brasil, lugar de onde Elza Freire e sua família saem para mapear cenários e viver experiências pelo mundo afora, criando cenas e registrando memórias entre os limites e as possibilidades da pesquisa.

Tal procedimento permite pensar o exílio, tendo de um lado o Estado - golpes e ditaduras de Estado e, portanto, questões políticas e coletivas; e de outro, a memória e experiências, mediatizadas pela Educação - atuação dos atores sociais. Neste caso, Elza Freire através de suas experiências de exílio (YANKELEVICH;JENSEN, 2007).

Experiências de exílio, que orientam o período em estudo, as análises preliminares do campo empírico e incluem o único texto publicado de Elza Freire, identificado até o momento, nele constam posicionamentos que inquietam, sobretudo do enfrentamento

Quando saí, senti que realmente não voltaria. Talvez isso me tivesse dado um certo corte, não pensar mais em voltar nem no que tinha deixado. Viver uma outra vida, diferente da que tinha passado. Talvez o momento mais duro tenha sido esse. O momento em que eu saí... Era como se tivesse tido a coragem de dizer: não existe daqui pra lá. (ELZA FREIRE in COSTA et al., 1980, p. 200)

Para Benjamin (1985), a experiência não se constitui no momento que se vive, mas no momento em que se transmite e, segundo Rollemberg (1999) suas simbologias e representações nos falam de situações, sentimentos e práticas recorrentes no tempo.

Há também a identificação de reflexões profundas que abrem possibilidades potentes de interpretação e certa comparação, tendo em vista que o mapeamento de campo tem início no Brasil em Recife, passando por Brasília; depois, as residências na Américas: Santiago/Chile e Nova York/Estados Unidos; a travessia do Atlântico e chegada na Europa em Genebra/Suíça, concomitantemente, os desdobramentos do trabalho 
político-pedagógico na África ${ }^{13}$, cenários que a pesquisa construiu para emoldurar essas experiências de Elza Freire, conforme ela aponta que

Nesses últimos anos vivi uma retomada de trabalho que para mim tem sido interessante. Refiro-me ao trabalho de alfabetização em países africanos, uma outra realidade. Já posso comparar com o que fizemos no Brasil. (ELZA FREIRE apud COSTA, et al., 1980, p. 200)

Portanto, o desenvolvimento central tem como escopo os percursos de Elza Freire entendendo-a por essas configurações sociais de tempo-espaço. Afinal, "estas pessoas constituem teias de interdependência ou configurações de muitos tipos, tais como famílias, escolas, cidades, estratos sociais ou estados" (ELIAS, 1999, p. 15).

A perspectiva analítica é articular o micro, o meso e o macro, ancorado em fatos, fotos, fragmentos e documentos históricos, a par das experiências vividas, com base na Família Freire. As fontes da pesquisa se intercalam para atribuir uma dimensão sensível aos sujeitos e significados aos cenários, com destaque aos depoimentos e assume proporções mais amplas que a nacional/territorial e a individual, em virtude das combinações e reflexões que dela emergem. Há também a busca por identificar e entender como essas experiências se reverteram em propostas e práticas políticopedagógicas de Elza Freire e de Paulo Freire deixadas como legado, tanto para a Educação nacional, quanto para a internacional.

\section{Muitos cenários - um tempo, uma época, uma mulher}

As décadas de 1960, 1970 e 1980 são fecundas e compõem os cenários nacional e internacional, em que foram inseridos brasileiros como parte de um processo que acometeu cidadãos exilados. As experiências de Elza Freire, se entrelaçam a essa realidade, marcada por desencadeamentos de fatos históricos, político-pedagógicos e socioculturais que provocaram rupturas e alteraram realidades de países e povos.

\footnotetext{
${ }^{13}$ Verificar Freire (1997, nota de rodapé p. 36) e Spigolon (2014, p. 285-354).
} 
A discussão se insere nesse momento, sendo que contempla uma investigação pautada em aspectos significativos do percurso de Elza Freire, sem alicerçar-se numa perspectiva biográfica. Elias adota determinada abordagem para superar a perspectiva biográfica, relacionando a dimensão individual à social, anunciando que "é preciso ser capaz de traçar um quadro claro das pressões sociais que agem sobre o indivíduo" (ELIAS, 1995, p. 18). Para isso, o esquivar de certa ilusão biográfica ao desenvolver a pesquisa não como "um conjunto coerente e orientado" (BOURDIEU, 1998, p. 184), e nem construir um "relato apaixonado".

Em breve retrospectiva, Elza Freire, mulher, nordestina, normalista, funcionária concursada; pioneira da arte-educação no ensino público por meio da alfabetização infantil, casou-se com Paulo Freire em 1944. Esposa, companheira, educadora, intelectual, mãe, amiga, exilada, solidária; engajada nas atividades sociais, políticas e culturais, nas causas educacionais e do trabalho libertador. Elza representou perda e saudade, dor em 1986.

Elza Freire foi mais que professora e diretora de escola, mais que esposa de Paulo Freire, foi mais que a companheira de todas as horas de um importante educador brasileiro e pensador mundial. Ela ao possibilitar a sua aproximação crítico-reflexiva com as questões educacionais o leva do Direito para a Educação. Ainda em Recife, foi sistematizadora das palavras geradoras para a Educação de Adultos; precursora da formação de educadores, depois em Brasília no PNA e o exílio com o golpe de 1964.

Elza Freire influenciou e concretizou com Paulo Freire seus sonhos e suas utopias, muito mais que companheira amorosa, esposa e mãe dedicada, profissional competente, exerceu grande e decisiva influência no pensamento e na práxis Freireana; bem como deixou importantes contribuições para a Educação Brasileira. Desse modo, dilata-se a percepção das relações entre os percursos individuais e as configurações do exílio.

Os referenciais e a abordagem em que se ancoram os campos teórico, metodológico e empírico ajudam a trazer para um diálogo inicial tais questões do casal Elza Freire e Paulo colhidos a partir dos processos e das experiências antes, durante e depois do exílio, por exemplo: os espaços públicos e privados ocupados e construídos. 
Portanto, examinar com atenção e cuidado os percursos de Elza Freire - como percursos de vida e como esses percursos produziram uma memória e um sentimento sobre e a partir de, com, como... levando inclusive à produção de práxis - pensamentos mais ação.

O exílio tornou-se decisivo na redefinição do país e das vidas exiladas.

Adotamos conceito amplo de exílio. Embora Elza Freire não tenha respondido inquéritos, decidimos categorizá-la como exilada ${ }^{14}$, aportando-nos na fundamentação de Costa [et al.,1980], pois assim como as autoras, entendemos que

São exiladas as perseguidas, as punidas, as presas e torturadas. São exiladas as que sofreram perseguições indiretas. Esposas, mães, filhas e amantes. São exiladas as que perderam suas condições de trabalho, também aquelas que não puderam suportar o sufoco numa sociedade onde a ditadura desenvolveu tantas formas de opressão. E ainda aquelas que teimaram em ser livres onde as liberdades estavam cerceadas (COSTA, et al., 1980, p. 18).

Para Rollemberg "o exílio no exílio", fundamenta que o exílio de Elza Freire e demais exilado(a)s brasileiro(s) se configura assim. Segundo ela, a perspectiva de volta se afastava junto com a América Latina e a necessidade de se adaptar a novo país: línguas, sobrevivência, militância, conduz de forma imperativa à "nova fase e redefinições. Os exilados se espalhando pelo mundo. A diáspora." (ROLLEMBERG, 1999, p. 88).

O mapa que traçamos a partir dos percursos de Elza Freire é denominado como Diáspora Freiriana, delineia rotas, traça deslocamentos e produz significados dessa diáspora ${ }^{15}$, considerada a maior diáspora política brasileira (RABÊLO, 2001).

\footnotetext{
${ }^{14}$ Com as autoras, adotamos a concepção de que a condição de exilada não se confunde com a de asilada ou refugiada, pois "o estatuto legal não cobre a diversidade de situações de exílio, nem abrange aquelas pessoas portadoras de documentos mas que não poderiam voltar em segurança, e cuja situação formal foi sempre bastante ambígua" (COSTA, et al., 1980, p. 18).

${ }^{15}$ Os processos de exílios provocaram circulação que experienciada por Elza Freire e sua família pode ser qualificada diaspórica, na proporção em que a memória individual e coletiva se liga concomitantemente à multiplicidade de lugares vividos na diáspora (BRUNEAU, 2009; CORTES \& FARET, 2009; COURGEAU, 1988; HALL, 2006).
} 


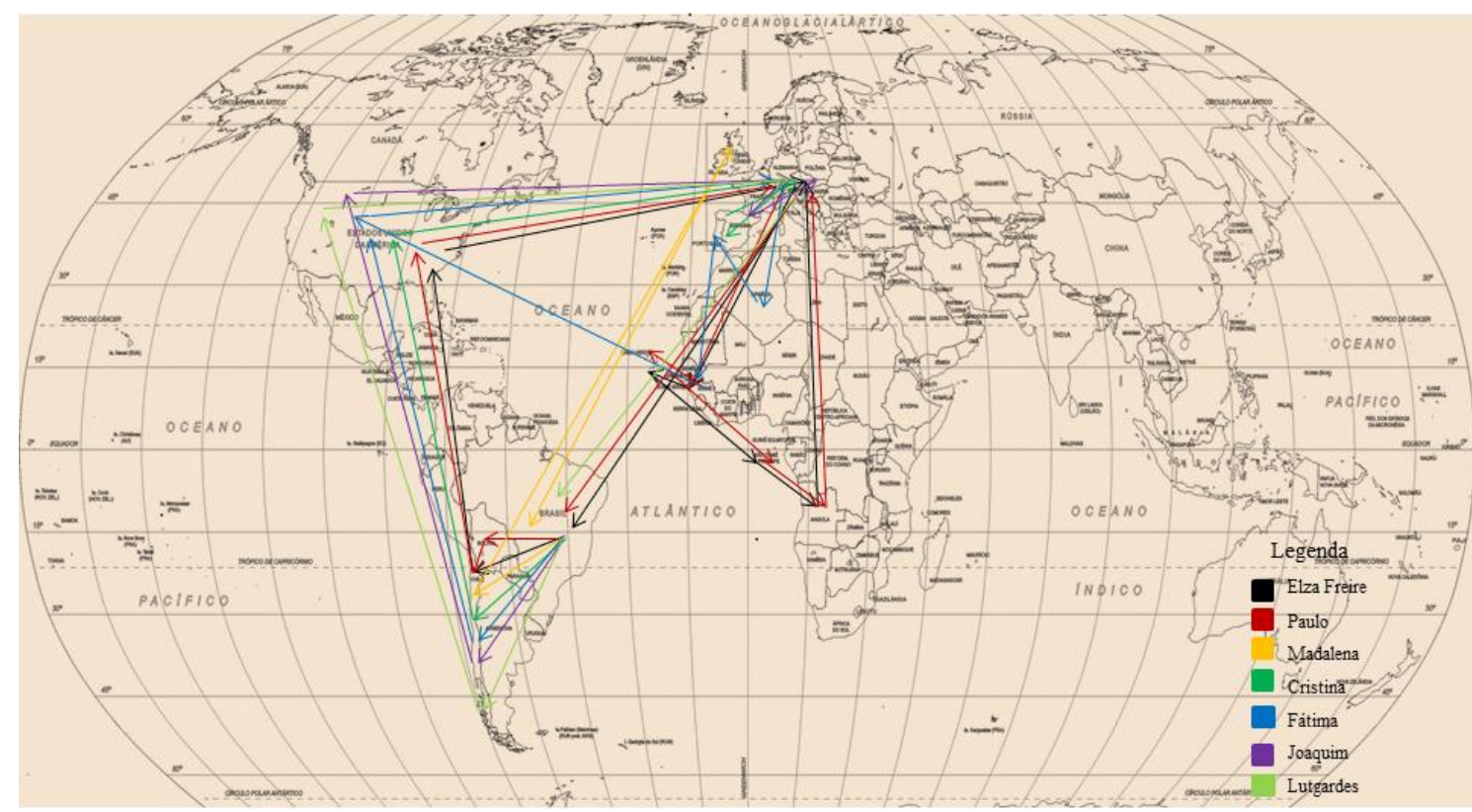

Figura 01 - Mapa da Diáspora Freiriana a partir dos percursos de Elza Freire durante a ditadura e o exílio brasileiro no período de 1964 a 1979, traçado pela autora como resultado de pesquisa.

Fonte: Disponível em SPIGOLON, 2014, p. 428.

Após o golpe de 1964 e imersos na ditadura e no exílio, que envolveu circulações seguidas por rotas internas e externas, as fronteiras para os Freires (Elza Freire, Paulo, Madalena, Cristina, Fátima, Joaquim e Lutgardes) se romperam de vez com a saída do Brasil a partir do golpe de 1964 e a ditadura. Inicialmente, pelas Américas, via América do Sul, com conexão na Bolívia, Chile e depois nos Estados Unidos. De lá, estabelecendo residência fixa na Suíça eles passam a circular pela Europa e África. Tais estratégias construídas a partir dos percursos de Elza Freire caracterizam uma diáspora em escala local que se amplia para a regional, nacional e internacional.

O quesito relevância se justifica em parte pela escassez de estudos que contemplem a temática; sobre Elza Freire, são desconhecidas pesquisas ${ }^{16}$.

Lopes (2000) considera incipiente a ideia de se produzir estudos específicos em torno das mulheres em ciências ${ }^{17}$. Para Fávero \& Britto (2002) existem poucas produções sobre a presença das mulheres, considerando as mulheres terem pouca visibilidade nos

\footnotetext{
${ }^{16}$ Fizemos levantamento junto a diversos bancos de dados, dentre eles: Coordenação de Aperfeiçoamento de Pessoal em Nível Superior, Arquivo Edgard Leuenroth, Memórias Reveladas.

${ }^{17} \mathrm{Na}$ tentativa de aproximar pesquisadores e leitores dessa temática, o Cadernos Pagu - Gênero, ciências e história, nº 15, 2000; apresentou dossiê editado por M. Margaret Lopes.
} 
quadros mais legítimos do campo educacional. No contexto do exílio, Rollemberg (1999) e Spigolon (2014) tecem considerações semelhantes. As autoras advertem que esse aspecto e peculiaridades podem ser objeto de investigações científicas.

Esse processo investigativo abre possibilidades para se verificar a presença contínua de mulheres brasileiras exiladas como Elza Freire - mulher, mãe, professora e, exilada, envereda por aspectos da pesquisa, numa perspectiva até então desconhecida; entre solidão e afazeres, países distintos; descobertas, impermanências - que ela experienciou, circunscrita a período que se distingue pela escassez de estudos referentes à Educação e exílio, mulheres professoras exiladas e, em especial o exílio brasileiro.

Cenários que ao expressarem além da cartografia geográfica, apresentam as Américas e, em especial a América Latina sob aspectos políticos, sócio-históricos, culturais e pedagógicos, para estabelecer discussões sobre os golpes, as ditaduras instauradas e os exílios nesse continente. As reflexões críticas assumem certo tom de protesto como utopia e opressão revolucionárias, como um movimento de transformação social, pois a "liberdade na América será filha de nossos feitos e de nossos pensamentos" (NERUDA, 2011, p. 170).

E atravessam o Atlântico para apresentar a Europa os deslocamentos da militância em decorrência das inserções do casal Freire - Elza e Paulo Freire, enquanto exilados políticos brasileiros junto aos primeiros governos dos recém-independentes Países Africanos de Língua Oficial Portuguesa - PALOP ${ }^{18}$, os quais apontamos, por exemplo, que se transformaram em camaradas.

Esse posicionamento individual e coletivo não desistoriciza o sujeito, ao contrário. O casal Elza e Paulo Freire passa a ser parte desses grupos, é a historicidade à qual eles são submetidos que mostra como são arremessados ao exílio, eles não optam. É o exílio que os torna militantes a tal ponto de os classificar militantes de esquerda, fazendo pousar, inclusive, sobre seus trabalhos e propostas político-pedagógicas o rótulo de esquerda e outros semelhantes. Elza e Paulo Freire, como outros que atuaram na África

\footnotetext{
${ }^{18}$ O acrónimo PALOP significa Países Africanos de Língua Oficial Portuguesa. É a expressão usada para se fazer referência aos cinco países africanos ex-colônias de Portugal: Guiné-Bissau, Cabo Verde, Angola, São Tomé e Príncipe e Moçambique e que obtiveram a independência entre 1973 e 1975.
} 
na condição de exilados políticos militantes, são considerados de esquerda por um conjunto de autores.

De algum modo, a radicalização das sistematizações das propostas políticopedagógicas do casal Elza Freire e Paulo é forjada nos caminhos do exílio brasileiro e da militância na África, considerando que as dinâmicas de seus trabalhos decorridos das inserções e atuações deles no âmbito daquelas realidades revelam o alinhamento com os movimentos revolucionários, mediado por situações em que o casal residindo na Europa envolveu-se com projetos de reconstrução nacional, sempre vinculados com Educação e, notadamente com a Alfabetização de Adultos.

Cenários que criam e recriam as ambiências e as conjunções do golpe civil-militar no Brasil, inserido nas configurações das ditaduras instauradas na América Latina e dos exílios, das travessias do Atlântico para a Europa e dos movimentos para libertação das colônias portuguesas na África, ambas são parte de processos de repressão e violência que acometeram povos e países, cujo recorte temporal se situa entre os anos de 1964 a 1979, em decorrência de ter sido o ano que marcou o primeiro retorno para visitar o país após 15 anos de exílio, pois o retorno definitivo se efetivou em 1980.

As discussões acerca dos processos sociais das ditaduras e do exílio ganham vulto, reconhecidos nas sociedades contemporâneas, com destaque na sociedade brasileira. Para tal, continuamos nos apropriando do percurso de Elza Freire e das configurações sui generis da Família Freire - que como sujeitos representam tantos outros, tendo como foco o exílio e a educação a partir das experiências individuais ante às circunstâncias coletivas vividas.

\section{(In) Conclusões}

Seja como for, a continuidade das MEMÓRIAS DO EXÍLIO é importante para a construção da memória nacional [...] Que esta esperança, este ideal de liberdade, seja assumido por um número cada vez maior de brasileiros e brasileiras!

Albertina de O. Costa, et. al. (apresentação, 1980) 
Neste trabalho, nos reportamos a fragmentos de resultados de pesquisa. São questões voltadas ao golpe de 1964, à ditadura e detidamente ao exílio brasileiro em diálogo permanente com as experiências individuais advindas desse processo social e coletivo, articuladas numa discussão entre as esferas do Estado e da Educação, cujos reflexos e reflexões nos convocam e provocam a pensar a Sociedade Brasileira na contemporaneidade.

A produção do texto envolve o entrelaçamento deles ao esforço coletivo para a construção de memórias da educação brasileira e do exílio brasileiro sob a inspiração da epígrafe acima, e que se dê com a conscientização ${ }^{19}$ crítica assumida num compromisso reassumido, de certa forma, por todos nós brasileiros e brasileiras e, em especial educadores, governos, pesquisadores, estudantes e entidades da sociedade civil que atuam e militam na área da Educação, nas esferas pública e privada, formal e não formal e que formulam, implementam e/ou avaliam políticas, projetos e práticas educacionais. É nesse processo e em sua continuidade que, reafirmamos, poderá se impedir ditaduras e governos autoritários que utilizam a repressão para violar a liberdade e cercear a democracia, instituir ditaduras e exílios.

Ao lidar com os percursos de Elza Freire e suas experiências de mulher exilada, em vários cenários, tempos e lugares, colocamo-nos em oposição às ditaduras no Brasil, na América Latina e no mundo, reafirmando-nos a favor de um projeto de Educação de corte universalista, libertária, pública, laica, democrática e de qualidade para todos, e que, sobretudo, vise à construção de sociedades mais justas, dignas, humanas e amorosas.

Acreditamos que recuperar memórias, investigar processos e experiências, é uma forma de resistir ao exílio, de impedir a repetição de terrorismos de Estado; é garantir a participação da Sociedade Civil, é recusar situações sociais de opressão, exclusão e violação de direitos; é fortalecer princípios de liberdade e vida, ideais que coadunam com a percepção da atuação de atores no mundo público e, em particular, Elza Freire.

\footnotetext{
${ }^{19}$ Adotamos e referimo-nos principalmente as conceptualizações de FREIRE, Paulo. Pedagogia do Oprimido. Porto: Afrontamento, 1972 e Conscientização. São Paulo: Centauro Editora, 2006 e um conjunto de autores que fundamentam tal arcabouço teórico.
} 
Numa espécie de tensão que a memória, a história e a pesquisa instalam, cabem indagações: por que o abuso do poder, da força, da violência? Para que serviu a coerção e a perseguição? Como re-significar o golpe, a ditadura, o exílio? Quais as repercussões para a sociedade brasileira? Quais os vestígios e testemunhos da estupidez que ainda nos cercam e como eles se manifestam ante à contemporaneidade?

As problemáticas sociais e educacionais, as angústias das desigualdades continuam. Questões que fizeram e fazem a realidade como desafio para o fato de que outra forma de existência e convivência precisa ser permanentemente construída, por mais individual que seja a experiência do sujeito, ela está inscrita na experiência coletiva e social.

Resta-nos a indignação, dizer não a esta deriva autoritária sob a forma do golpe de 1964 e à ditadura, expor sua arrogância e falsidade. A indignação é um sentimento de repulsa, retira-nos da passividade, recorda-nos que o presente é frágil e as conquistas que conhecemos nada têm de perenes, permanentes.

\section{Referências}

BEISIEGEL, Celso de Rui. Estado de educação popular. São Paulo: Pioneira, 1974.

BEISIEGEL, Celso de Rui. Política e educação Popular: a teoria e a prática de Paulo Freire no Brasil. São Paulo: Ática, 1982.

BENJAMIN, Walter. Obras escolhidas: magia e técnica, arte e política. São Paulo: Editora Brasiliense, 1985.

BOURDIEU, Pierre. A ilusão biográfica. In: AMADO, J.; FERREI.RA, M. de M. (Orgs.). Usos e abusos da história oral. Rio de Janeiro: FGV, 1998.

BRUNEAU, Michel. Pour une approche de La territorialité internationale: lês notions de disapora et de communité transnationale. In: ARAB, C. et al. Les circulations

transnationales: lire les turbulences migratoires contemporaines. Paris: Armand Colin, 2009, p. 29-42, 
BRÜHL, Dieter. Método científico e objeto nas ciências sociais: algumas reflexões sobre o caráter dialético do processo de pesquisa em Ciências Sociais. [19--]. (Mimeo).

CORTES, Genevière.; FARET, Laurent. La circulation migratoire dans "l'ordre dês mobilités. In: ARAB, C. et al. Les circulations transnationales: lire les turbulences migratoires contemporaines. Paris: Armand Colin, 2009.

COSTA, Albertina de Oliveira. et al. (Orgs.). Memórias das mulheres do exílio. Rio de Janeiro: Paz e Terra, 1980.

COURGEAU, Daniel. Methodes de mesure de la mobilité spatiale: migrations internes, mobilité temporaire, navettes. Paris: Editions de l'Institut national d'etudes demographiques, 1988.

CUNHA, Luiz A.; GOÉS, Moacyr de. O golpe na educação. Rio de Janeiro: Editora Zahar, 1985.

DREIFUSS, René Armand. 1964 a conquista do Estado: ação política, poder e golpe de classe. Petrópolis: Vozes, 2008.

ELIAS, Norbert. Introdução à sociologia. Lisboa: Edições 70, 1999.

ELIAS, Norbert. Mozart, sociologia de um gênio. Rio de Janeiro: Jorge Zahar Editor Ltda, 1995.

ELIAS, Norbert. Sobre o tempo. Rio de Janeiro: Jorge Zahar Editor Ltda, 1998.

FREIRE, Elza. Setembro de 1977. In: COSTA, A. de O. et al. (Orgs.). Memórias das mulheres do exílio. Rio de Janeiro: Paz e Terra, 1980.

FREIRE, Paulo. A importância do ato de ler: em três artigos que se completam. São Paulo: Cortez: 1997.

FREIRE, Paulo. Educação como prática da liberdade. Rio de Janeiro: Paz e Terra, 1967.

FÁVERO, Maria de Lourdes A.; BRITTO, Jader de Medeiros (Orgs.). Dicionário de educadores no Brasil: da Colônia aos dias atuais. Rio de Janeiro: Editora UFRJ: MEC/INEP/COMPED, 2002.

FÁVERO, Osmar. Cultura popular, educação popular, memória dos anos 60 . Rio de Janeiro: Grall, 1983. 
FERNANDES, Florestan. A revolução burguesa no Brasil: ensaio de interpretação sociológica. Rio de Janeiro: Editora Jorge Zahar, 1975.

FERNANDES, Florestan. Prefácio. In: PEREIRA, L. A escola numa área metropolitana. São Paulo: FFCL/USP, 1960.

GALEANO, Eduardo. As palavras andantes. Porto Alegre: L\&PM, 2007.

GORENDER, Jacob. Combates nas trevas: a esquerda brasileira, das ilusões perdidas à luta armada. São Paulo: Ática, 1987.

HALL, Stuart. Da diáspora: identidades e mediações culturais. Belo Horizonte: Editora UFMG, 2009.

LARROSA, Jorge. Notas sobre a experiência e o saber da experiência. Revista Brasileira de Educação, Rio de Janeiro: ANPED, n. 19, 2002.

LEFEBVRE, Henri. Espaço e política. Belo Horizonte: Ed. UFMG, 2008.

LOPES, Maria Margaret. Apresentação. In: Inserir nome do autor. Gênero, ciências e história. Cadernos Pagu, Campinas: Gráfica do IFCH/UNICAMP, n.15, 2000.

MAZZA, Débora. A produção sociológica de Florestan Fernandes e a problemática educacional: uma leitura (1941-1964). Taubaté: Cabral Editora e Livraria Universitária, 2003.

NERUDA, Pablo. Para nascer nasci. Rio de Janeiro: Editora Bertrand Brasil Ltda, 2011.

NOGUEIRA, Oracy A. Problema social e problema de investigação. Revista Educação e Ciências Sociais. Rio de Janeiro: INEP, Vol. III, nº 8, 1958.

PAIVA, Vanilda. Educação popular e educação de adultos, contribuição à história da educação brasileira. São Paulo: Loyola, 1973, p. 207.

PEPETELA [PESTANA, Artur Carlos Maurício]. A geração da utopia. Lisboa: Dom Quixote, 1997.

RABÊLO, José Maria; RABÊLO, Theresa. Diáspora: os longos caminhos do exílio. São Paulo: Geração Editorial, 2001.

REZENDE, Maria José de. A ditadura militar no Brasil: repressão e pretensão de legitimidade 1964-1984. Londrina: Editora UEL, 2001. 
ROLLEMBERG, Denise. Exílio entre raízes e radares. Rio de Janeiro: Record, 1999.

SAID, Edward. W. Reflexões sobre o exílio e outros ensaios. São Paulo: Companhia das Letras, 2003.

SANFELICE, José Luís. O Manifesto dos educadores (1959) à luz da história. Educação \& Sociedade, Campinas/SP v.28, n.99, maio/ago., 2007.

SPIGOLON, Nima. I. Pedagogia da convivência: Elza Freire - uma vida que faz Educação. 2009. Dissertação (Mestrado em Educação) - Universidade Estadual de Campinas, Campinas, 2009.

SPIGOLON, N. I. As noites da ditadura e os dias de utopia: o exílio, a educação e os percursos de Elza Freire nos anos de 1964 a 1979. Tese (Doutorado em Ciências Sociais na Educação) - Universidade Estadual de Campinas, Campinas, 2014.

VALLE, Maria Ribeiro do. 1968: o diálogo é a violência - movimento estudantil e ditadura militar no Brasil. Campinas: Editora da UNICAMP, 2008.

VÁZQUEZ, Adolfo Sánchez. Entre a realidade e a utopia: ensaios sobre política, moral e socialismo. Rio de Janeiro: Civilização Brasileira, 2001.

VITA, Álvaro de. Sociologia da sociedade brasileira. São Paulo: Editora Ática, 2001.

TOLEDO, Caio Navarro de. O governo Goulart e o golpe de 1964. São Paulo: Brasiliense, 1982.

WEFFORT, Francisco C. O populismo na política brasileira. Rio de Janeiro: Paz e Terra, 1978.

YANKELEVICH, Pablo (Org.). Represión y destierro: itinerarios del exílio argentino. Buenos Aires: Ediciones Al Margem, 2004.

YANKELEVICH, Pablo (Org.). México, país refugio: la experiência de los exilios em el siglo XX. México: INAH/Plaza y Valdés, 2002.

YANKELEVICH, Pablo ; JENSEN, Silvina (Orgs.). Exilios: destinos y experiências bajo la dictadura militar. Buenos Aires: Libros Del Zorzal, 2007. 
Recebido em: 15/09/2016 Aprovado em: 21/11/2016

Universidade do Estado de Santa Catarina - UDESC Centro de Ciências Humanas e da Educação - FAED

Revista PerCursos

Volume 17 - Número 35 - Ano 2016 revistapercursos@gmail.com 